\title{
An experimental device designed to obtain repeatable condensation peaks in a closed system
}

\author{
U. Soupremanien ${ }^{1}$, E. Ollier ${ }^{1}$, N. Salamon ${ }^{1,2,3}$, \\ S. Monfray ${ }^{3} \&$ T. Skotnicki ${ }^{3}$ \\ ${ }^{1}$ CEA/DTNM/SERE/LRME, France \\ ${ }^{2}$ TUL, Department of Semiconductor and Optoelectronics Devices, \\ Poland \\ ${ }^{3}$ STMicroelectronics (Crolles 2), France
}

\begin{abstract}
The results of an experimental study related to repeatable condensation peaks in a closed system are presented and a discussion to describe their incipiencies is detailed. The test sections (D1: filling capacity $=15.14 \times 1 \mathrm{e}^{-9} \mathrm{~m}^{3}$; D2: filling capacity $=6.45 \times 1 \mathrm{e}^{-9} \mathrm{~m}^{3}$ ) were divided into three parts: an evaporator, an insulator and a conductive top cover where a pressure sensor was inserted. The impacts of several parameters have been studied: devices' filling ratio $(\alpha)$; hot temperature of the evaporator; cooling of the condensation chamber and; the devices' dimension. For all the obtained results the frequencies were low $(<0.15 \mathrm{~Hz})$ but the peak pressure amplitudes were significant (up to 987 mbar). The influence of $\alpha$ had been studied and its increase led to an augmentation of the pressure amplitude (exponential-like function) but to a decrease in the oscillation frequencies. The hot temperature's increase enhanced the oscillation frequency but the pressure amplitude variations were slightly decreased. The cooling level diminution led to a frequency decrease, but to a slight variation of the pressure peak amplitude. Reducing the devices' dimensions from D1 to D2 for the same $\alpha$ and cooling level allowed the increasing of the oscillation frequency without significantly modifying the pressure peaks' amplitude. In a strategy for energy harvesting these oscillation peaks could be converted into electricity using piezo-electrics.
\end{abstract}

Keywords: oscillations, pressure peaks, energy harvesting, condensation implosion, evaporation, phase-change. 


\section{Introduction}

The progress made in miniaturization has highly reduced the power required to work electronic systems and has opened the way to zero-power electronics (no batteries) [1]. One of the key technologies for the future smart systems concerns wireless sensors. In order to power these systems, energy harvesting from the environment has become a relevant challenge. Waste heat is one of the most significant sources of energy and trials for its conversion into electricity have begun. Until now, most of the well-known thermal harvesters are based on the Seebeck effect [2]. The two main drawbacks of Seebeck technology are: (1) the "good" thermal conductivity (generally due to good electrical properties) of the device which makes the maintenance of the thermal gradient difficult without the use of large heat sinks; (2) the need for rare materials.

Due to these drawbacks, new concepts have emerged to harvest waste heat [3-8]. Recently, many attempts for realizing MEMS comprising liquid/vapor phase change have been done. Most of the time the architecture remains simple and presents a planar shape with two diaphragms and a working liquid entrapped between them $[3,4]$. One of the first prototypes presenting this architecture seems to be the $\mathrm{P}^{3}$ micro-engine realized by Whalen et al. [4]. The engine core was comprised between two diaphragms of silicon spaced at $60 \mu \mathrm{m}$ (Figure 1a). A vapor bubble of 3MTM PF-5060DL was introduced between these diaphragms. Heating pulses were generated in order to drive (or not) the heat through the device. Oscillation frequencies of more than $400 \mathrm{~Hz}$ were reached in this study with an increase in typical pressures of $10 \mathrm{kPa}$.

a)

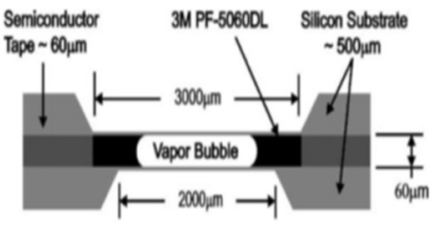

b)

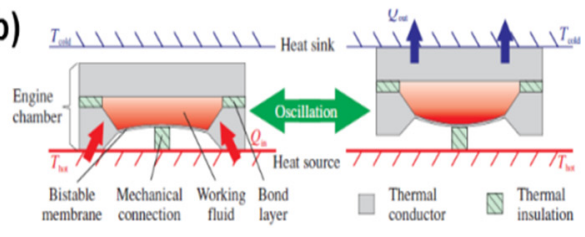

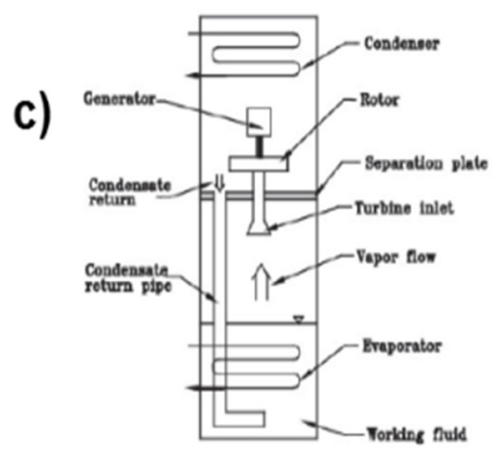

Figure 1: a) Cross section of the prototype using the typical PCMHE architecture from [4]; b) oscillation due to phase change and bistable from [5]; c) micro-vibrations from [6]. 
Another technique (Figures $1 \mathrm{~b}$ and 1c) using phase-change phenomena to also harvest energy has been reported. Huesgen et al. [5] used a bistable material in order to connect their device to the cold source, when vapor appears due to vaporization and connect it to the hot source when this vapor turns to liquid. For a temperature difference of $37^{\circ} \mathrm{C}$ the oscillation frequency reaches $0.71 \mathrm{~Hz}$. All these studies usually used an additional oscillating media in order to conduct the heat for the oscillations' control. A promising system using a constant source of heat to produce energy had also been reported $[1,7,8]$. The system consisted of a bimetal, which can suddenly hit a piezo-electric element in order to produce energy. The sudden mechanism of snapping could be realized for different ranges of temperatures (depending on the materials used) and its origin comes from the shape of the bimetal. Puscasu et al. [8] put forward a scaling law which opened the way for the miniaturization of this technology.

The main goal of this study was to realize an oscillating system only controlled by a constant source of heat. These kind of oscillating conditions have already been obtained in literature. Usually the systems which used them are employed to transfer large amounts of heat. Indeed, a pulsating heat pipe (PHP) could achieve this oscillating behavior. These technologies have been studied since the 80 s and already given promised results in electronics' cooling as shown in $[9,10]$. The oscillation mechanisms, which occurred in pulsating heat pipes (that have a very simple architecture), are interesting. Indeed, a tube partially filled with a working liquid is used. The thermal boundary conditions to make the system work could be a constant source of heat and a cold source. The start-up of the system is initiated for a sufficient amount of heat regarding a specific filling ratio $(\alpha)$. The oscillations are due to heat and mass transfer between the liquid and vapor slugs. Several studies [9-13] have been conducted of the working of this technology and some general remarks can be given.

For tube diameters that are too low, Lin et al. [11] demonstrated that the heat flux needed for generate oscillations was increased (with water used as working fluid). Moreover for a tube diameter inferior to $0.4 \mathrm{~mm}$ the oscillations were not observed. These oscillations stop with diameter reduction were also observed by Lips et al. [12]. In order to make PHP work properly the authors calculated that the internal diameter of the tube needs to fulfill the following requirement:

$$
d_{h}<C \sqrt{\frac{\sigma}{g\left(\rho_{l}-\rho_{v}\right)}}
$$

where $d_{h}$ equals the hydraulic diameter, $g$, the constant of gravitation, $\sigma$ the liquid surface tension, $\rho$ the liquid or vapor density. The usual values of $\mathrm{C} \approx 2$ are generally given.

Commonly the PHP loops have a serpentine shape, which comprised several turns. The numbers of turn could have an impact on the PHP performances. Lips et al. [12] showed that for less than 4 turns the thermal performances of a PHP could be decreased. Lin et al. [11] also demonstrated that when the length of the tube was smaller, the starting-up of the PHP was facilitated. Many other parameters also had an impact on the PHP working, such as: orientation (vertical or horizontal), the fact that PHP is open or closed, the working fluid, the filling ratio etc. 
Khandekar et al. [13] demonstrated that with a simple set-up consisting of a single closed loop of capillary dimensions it was possible to obtain an oscillating behavior. The authors established that the oscillation of different frequencies in the range 0.1 to $3 \mathrm{~Hz}$ could be achieved with such a device. Even though the frequencies are generally known in PHP the value of the pressure variation during these oscillations is usually not given.

Studies related to systems using liquid-vapor phase change, specifically in condensation situations, have also reported many sudden pressure variations $[14,15]$. These phenomena are generally named: condensation induced water hammer (CIWH). Most of the time, this phenomenon appears for two-phase flow at a low flow rate and for stratified conditions. Due to the instabilities at the vapor/liquid interface a steam of vapor could be trapped between two liquid slugs and could collapse, leading to large pressure variations in the system.

Other condensation situations could lead to pressure variation. The mechanism of droplet grow rate has been studied by Rogers et al. [16] during heterogeneous vapor condensation. The authors found that the radius evolution of a condensing droplet was highly increased for coalescence conditions compared to an isolated condensing droplet (for a same time scale). In the present study specific oscillations due to a sudden decrease in pressure in a closed chamber were obtained in a configuration that has not yet been presented in the literature to the best of our knowledge. The oscillations were obtained for passive conditions (heat was not oscillating) and a parametric study is presented in order to better understand this mechanism.

\section{Experimental setup and characterizing method}

\subsection{Set-up description and experimental procedure}

The source temperature range was between $115^{\circ} \mathrm{C}$ and $145^{\circ} \mathrm{C}$ and the selected heated surface was $40 \times 40 \mathrm{~mm}^{2}$. The conditions for the environment were ambient. The tests sections are separated into three parts: the evaporator (made in stainless steel 316), an insulator (made in polyether ether ketone: PEEK) and a top cover (made in stainless steel 316) where a pressure sensor (KELLER 35 X HTC) was inserted. The mains thermo-physical of the materials used in this study have been reported in Table 1.

Table 1: Thermo-physical properties of materials.

\begin{tabular}{|c|c|c|c|}
\hline Material & $\rho(\mathrm{kg} / \mathrm{m} 3)$ & $\lambda(\mathrm{W} / \mathrm{m} / \mathrm{K})$ & $\mathrm{C}_{\mathrm{p}}(\mathrm{J} / \mathrm{kg} / \mathrm{K})$ \\
\hline Stainless steel 316 & 8000 & 16.3 & 500 \\
\hline Peek & 1320 & 0.245 & 2010 \\
\hline
\end{tabular}

Deionized water (not degassed) had been used as the working fluid. The main thermo-physical properties of the working fluid have been calculated (using REFPROP) and summarized in Table 2 for different saturation pressures. 
Table 2: Thermo-physical properties of water for different saturation pressures.

\begin{tabular}{|c|c|c|c|c|}
\hline WATER & $\begin{array}{c}\mathrm{P}_{\text {sat }} \approx 1 \text { bar } \\
\mathrm{T}_{\text {sat }}=100^{\circ} \mathrm{C}\end{array}$ & $\begin{array}{c}\mathrm{P}_{\text {sat }} \approx 2 \text { bar } \\
\mathrm{T}_{\text {sat }}=120.4^{\circ} \mathrm{C}\end{array}$ & $\begin{array}{c}\mathrm{P}_{\text {sat }} \approx 3 \text { bar } \\
\mathrm{T}_{\text {sat }}=133.7^{\circ} \mathrm{C}\end{array}$ & $\begin{array}{c}\mathrm{P}_{\text {sat }} \approx 4 \text { bar } \\
\mathrm{T}_{\text {sat }}=143.7^{\circ} \mathrm{C}\end{array}$ \\
\hline$\rho_{\mathrm{l}}(\mathrm{kg} / \mathrm{m} 3)$ & 958.37 & 942.77 & 931.69 & 922.78 \\
\hline$\rho_{\mathrm{v}}(\mathrm{kg} / \mathrm{m} 3)$ & 0.5976 & 1.1361 & 1.6577 & 2.1694 \\
\hline $\mathrm{h}_{\mathrm{lv}}(\mathrm{kJ} / \mathrm{kg})$ & 2256.4 & 2200.9 & 2163.0 & 2133.0 \\
\hline $\mathrm{C}_{\mathrm{pl}}(\mathrm{kJ} / \mathrm{kg} / \mathrm{K})$ & 4.2156 & 4.2442 & 4.2689 & 4.2913 \\
\hline $\mathrm{C}_{\mathrm{pv}}(\mathrm{kJ} / \mathrm{kg} / \mathrm{K})$ & 2.0799 & 2.1794 & 2.2641 & 2.3406 \\
\hline$\lambda_{\mathrm{l}}(\mathrm{W} / \mathrm{m} / \mathrm{K})$ & 0.6790 & 0.6832 & 0.6835 & 0.6829 \\
\hline$\lambda_{\mathrm{v}}(\mathrm{W} / \mathrm{m} / \mathrm{K})$ & 0.0250 & 0.0275 & 0.0292 & 0.0306 \\
\hline$\sigma(\mathrm{mN} / \mathrm{m})$ & 58.917 & 54.884 & 52.174 & 50.072 \\
\hline
\end{tabular}

In order to better understand the working of the oscillations, two geometries have been tested (Figure 2).

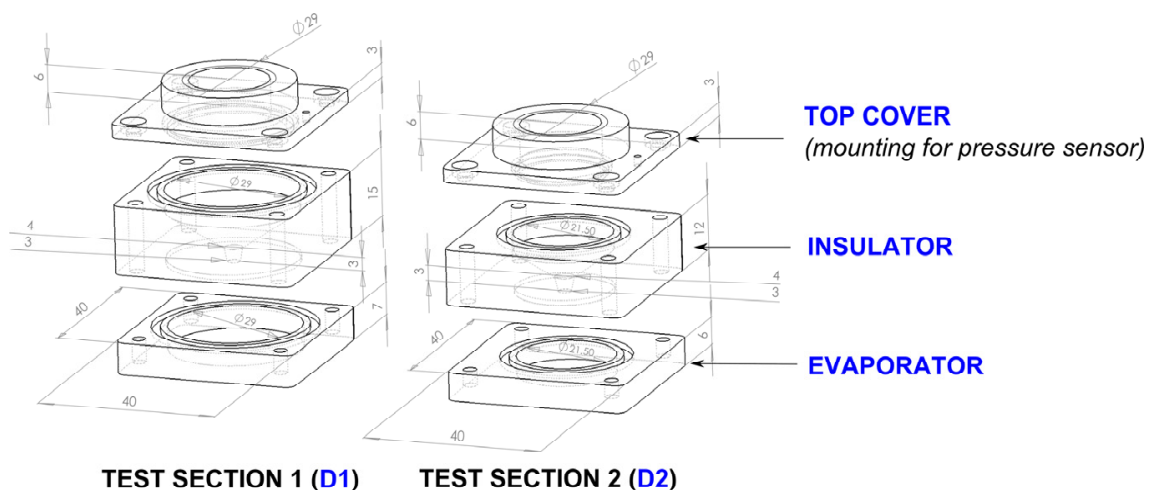

Figure 2: Schematic of the test sections used with main dimensions.

The O-rings' grooves which allow to avoid gas or liquid leakage, are clearly visible in Figure 2. The main parameters for the main volumes and lengths are summarized in Table 3.

Table 3: Comparison of test sections geometry.

\begin{tabular}{|c|c|c|c|c|c|c|}
\hline $\begin{array}{c}\text { Test } \\
\text { sections }\end{array}$ & $\begin{array}{c}\mathrm{h}_{\text {total }} \\
(\mathrm{mm})\end{array}$ & $\begin{array}{c}\mathrm{h}_{\text {insulator }} \\
(\mathrm{mm})\end{array}$ & $\begin{array}{c}\mathrm{V}_{\text {total }} \\
(\mathrm{ml})\end{array}$ & $\begin{array}{c}\mathrm{V}_{\text {condensation }} \\
(\mathrm{ml})\end{array}$ & $\begin{array}{c}\mathrm{V}_{\text {evap }} \\
(\mathrm{ml})\end{array}$ & $\begin{array}{c}\text { Ratio } \\
\mathrm{V}_{\text {cond }} / \mathrm{V}_{\text {evap }}\end{array}$ \\
\hline $\mathrm{D} 1$ & 31 & 15 & 15.14 & 12.38 & 2.64 & 4.68 \\
\hline $\mathrm{D} 2$ & 27 & 12 & 6.45 & 5.23 & 1.09 & 4.81 \\
\hline
\end{tabular}

The main objective of this fabrication is based on the fact that the device must be built without any moving or rotary parts. Using this fabrication strategy the devices can be realized easily and with cheap materials. The experimental bench (Figure 3) comprised a heater from MINCO (HM6815: $12 \Omega$ ), a flux-meter from CAPTEC (linear, precision: $3 \%$ ) which was also able to measure the temperature using a type-T thermocouple (hot temperature). The pressure variations were 
measured with a pressure sensor from KELLER (35 X HTC, full scale: 3bar; precision: $0.5 \%$ ). Before each experiment, the flux-meter surface was cleaned using alcohol, dry with pressurized $\mathrm{N}_{2}$ and then a thin layer of thermal grease (CW7270) was put on its two surfaces to ensure a good thermal contact with heater and test sections. Thereafter, the selected test sections were lain down on the flux-meter which was between the test section and the hot source. The heating power was regulated using a PID controller which was driven by a LABVIEW ${ }^{\circledR}$ program. The driving temperature was measured using a K-type thermocouple which was inside an aluminum block (above the heater). Finally a K-type thermocouple was used to measure the cold temperature on the device top's surface (Figure 3). In order to cool down the test sections a fan was put above the top cover. The distance between the top cover and the fan was set at $12 \mathrm{~cm}$.

a)

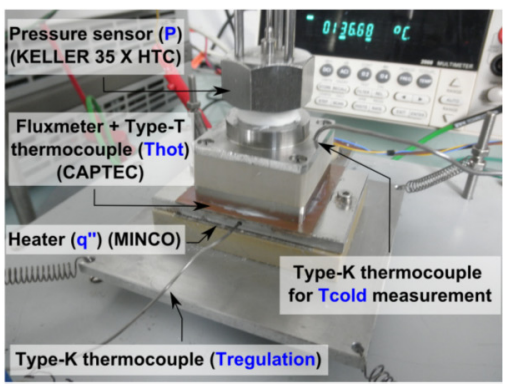

b)

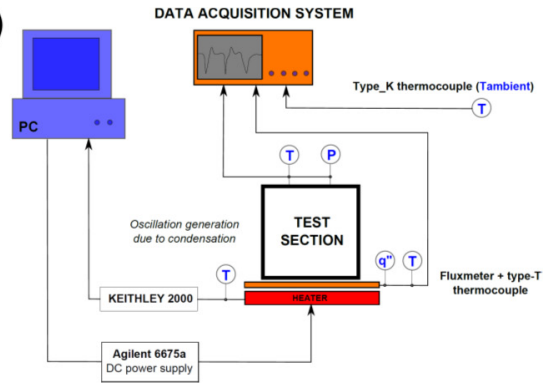

Figure 3: a) Test section; b) experimental facility.

\subsection{Study of specific parameters}

As for PHP, some parameters were suspected to have an influence on the oscillations. For this study the parameters, which had been varied, are the:

a. volume of water (filling ratio);

b. value of hot temperature;

c. cooling level.

\section{Oscillations mechanism}

During the experiments, for the specific range of filling ratio $(\alpha)$ the oscillations appear in the test sections when the heat flux was applied. The filling ratio can be expressed as following:

$$
\alpha=\frac{V_{l}}{V_{t}}
$$

where $V_{l}$ is the liquid volume and $V_{t}$ is the total volume available.

In order to check the leak-tightness, when the test sections were closed, the pressure variations were analyzed and the experiments were started only when its value remained stable. All our experimental points were analyzed for minimum time duration of 1 hour when the oscillating behavior was stabilized. The pressure and heat flux signatures usually evolved as shown in Figure 4. 
a)

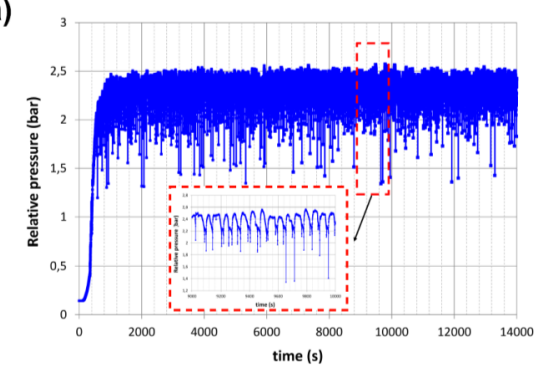

b)

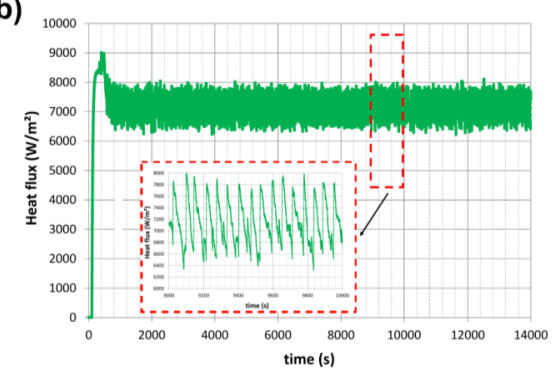

Figure 4: a) Pressure; b) heat flux signatures for D1 $\left(V_{l}=2000 \mu \mathrm{L}\right.$ and $T_{h o t}=$ $130^{\circ} \mathrm{C}$ ). Mean pressure amplitude variation $=345.5$ mbar; Mean heat flux variation $=900.0 \mathrm{~W} / \mathrm{m}^{2}$.

The pressure peaks amplitude $(\delta \mathrm{P})$ and the heat flux variations $(\delta \mathrm{q}$ ') were synchronized (with a small lag) (Figure 4). All the oscillating signals were analyzed using the PWELCH method (with MATALB ${ }^{\circledR}$ ) in order to determine the power spectral density and detect the peaks frequency.

According to our observations, the oscillating behavior could be detailed in following the steps, presented in Figure 5.

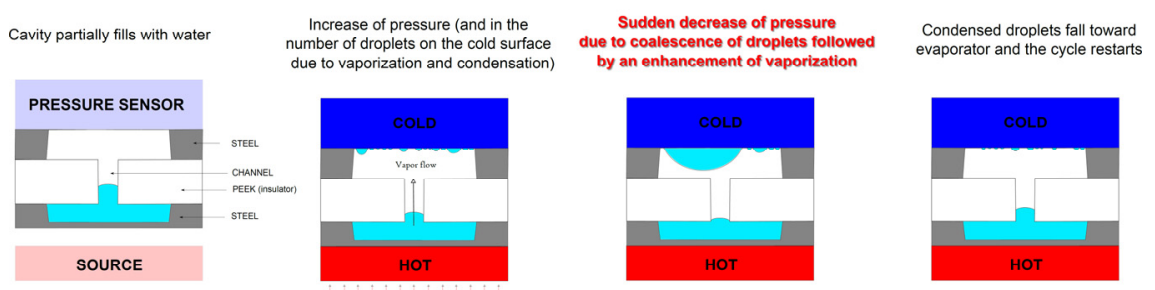

Figure 5: The working cycle of the oscillating device.

The oscillations were controlled by evaporation and condensation rates and specifically by the shape of the test sections. The pressure peaks were clearly due to condensation because of the orientation of pressure signature during the peak. These peaks were due to sudden condensation. As calculated by Rogers et al. [16] the radii of single droplets submitted to heterogeneous vapor condensation grows much slower than the radius of the equivalent droplet resulting from the coalescence of multiple droplets in condensation.

By considering the vapor volume, the oscillating cycle comprised four steps. In our test section the behavior could be expressed as the following: 1) after the pressure peak, a compression of the vapor occurred during which the temperature decrease; 2) the pressure reaches a "plateau" (a small time during which the condensation rate and the evaporation rate have almost the same value); 3) after this step the pressure decreases slowly because of a lower evaporation rate. Indeed due to the geometry all the condensed liquid does not return immediately to the evaporator. During the condensation process small droplets are in formation on 
the cold surface (pressure sensor surface) and their diameters increase slowly; 4) the droplets on the cold surface could suddenly coalesce and the pressure decrease sharply due to the fact that more vapor turns into liquid. Then, due to this sudden pressure decrease, the rate of vaporization of the liquid, in contact with a hot surface, highly increase leading to a pressure increase. During this time a significant increase in the heat flux (an also a decrease in hot temperature) have been observed.

\section{Results and discussion}

\subsection{Influence of volume on oscillations}

For D1 and D2 a clear variation of the oscillation had been observed with $\alpha$.

When $\alpha$ was increased, the amplitude of the pressure drop variations increased. On the contrary the frequency generally decreased with $\alpha$. This behavior could be explained by the fact that the condensation process is slowed down when the liquid volume is increased. Indeed, the mean pressure in the system increases with $\alpha$. Owing to this pressure evolution, the temperature at which the condensation occurred also increased leading to a decrease in the condensation rate for the same cooling conditions. Indeed, the heat transport toward the cold surface was slowed down and the cold temperature generally decreased with $\alpha$ for same boundary conditions (Figure 6).

a)

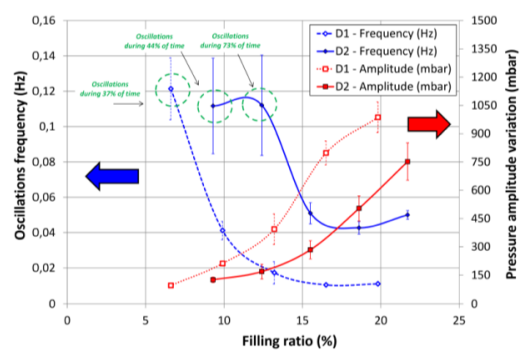

b)

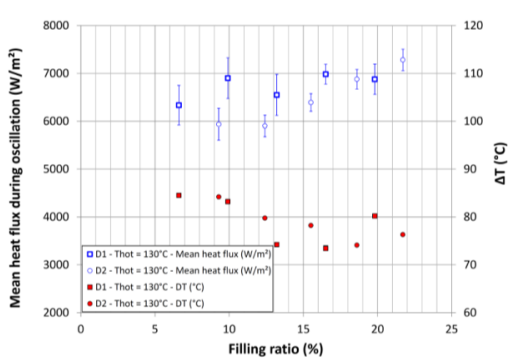

Figure 6: a) Volume impact on pressure amplitude and oscillations for D1 and $\mathrm{D} 2$ at $\mathrm{T}_{\text {hot }}=130^{\circ} \mathrm{C}$; b) Impact of filling ratio on heat flux and $\Delta \mathrm{T}$.

Below $1000 \mu \mathrm{L}(\mathrm{D} 1, \alpha=6.61 \%$ ) or below $800 \mu \mathrm{L}$ (D2, $\alpha=12.41 \%$ ), the oscillations were not fully continuous and a specific behavior with stopovers had been observed (Figure 7). This effect could be explained by the fact that water could, for low $\alpha$, totally evaporate on the hot surface. Even though liquid is still present in the system (partial pressure is not sufficient to suspect that water totally turns to vapor) it can be assumed that during a period the liquid droplets were stuck in the condenser part. Indeed in order to return back to the evaporator the pressure head of the liquid should overcome the capillarity pressure:

$$
\rho_{l} g H>\frac{2 \sigma \cos (\theta)}{r}
$$


where $g$ is the gravitational constant, $\theta$ the contact angle between liquid and PEEK (around $110^{\circ}$ for water at $25^{\circ} \mathrm{C}$ ) and $r$ the capillary radius. Indeed in order to fulfill the conditions of eqn $3, H>1.216 \mathrm{~mm}$.

During these waiting times, no oscillations occurred in the device. Nevertheless due to the fact that oscillations continued after theses bulges, a peak frequency was obtained at $0.1163 \mathrm{~Hz}$ here. All the volumes for which these waiting times were observed are circled and the respected percentage of time oscillation duration had been written near the corresponding values.

a)

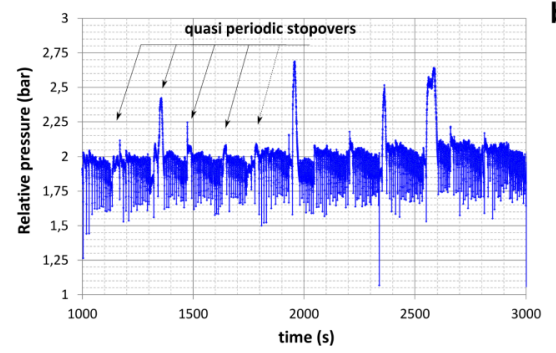

b)

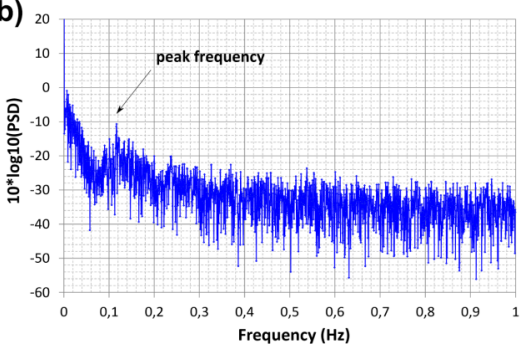

Figure 7: Visualization of the oscillations (and stopovers) for D2 and for $\alpha=12.41 \%$ for $\mathrm{T}_{\text {hot }}=130.6^{\circ} \mathrm{C}$; Peak frequency $=0.1163 \mathrm{~Hz}$; Mean pressure variation $=177.7$ mbar.

The influence of the dimensions on oscillations was analyzed (Figure 6). Indeed, it was possible to observe that with the reduction of the test section (D1 to D2) the peak oscillation frequency shift toward a higher frequency, whereas the pressure amplitude decreased as presented in Figure 6. This was due to the fact that for a smaller equivalent hydraulic diameter (D2 compared to D1) but the same heat flux, the vaporization rate is higher.

\subsection{Influence of hot temperature}

The hot temperature impact was also analyzed in this study. The range of the studied temperature was set between $115^{\circ} \mathrm{C}$ and $140^{\circ} \mathrm{C}$ (Figure $8 \mathrm{a}$ ).

a)

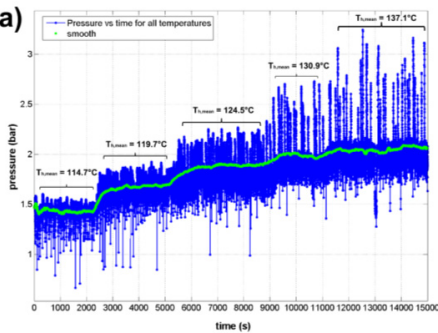

b)

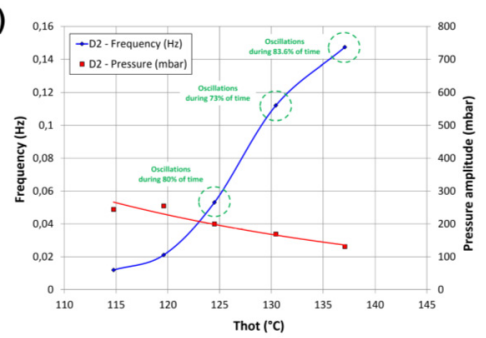

Figure 8: a) Pressure signature evolution with increase of temperature for D2;

b) impact of hot temperature on oscillations behavior $\alpha=12.41 \%$ for $\mathrm{D} 2(\mathrm{~V}=800 \mu \mathrm{L})$. 
As temperature increases the oscillating frequency also highly increase (from $0.012 \mathrm{~Hz}$ at $115^{\circ} \mathrm{C}$ to $0.147 \mathrm{~Hz}$ at $137^{\circ} \mathrm{C}$ ). In the same time the bulges (see Figure 7) get more amplitude. Nonetheless even with these stops, oscillation duration time last more than $73 \%$ of the time when $\mathrm{T}_{\text {hot }}>125^{\circ} \mathrm{C}$. Thus, the hot temperature increase had positive impact (increase in vaporization rate) on oscillation frequency. In the other hand, pressure variation amplitude decreased slightly.

\subsection{Influence of cooling}

In order to estimate the influence of cooling on the behavior of the system, the fan velocity was decreased gradually. The heat exchange coefficient was calculated using:

$$
h_{\text {conv }}=\frac{q_{\text {loss }}^{\prime \prime}}{S\left(T_{\text {cold }}-T_{a m b}\right)}
$$

The evolution of pressure, hot and cold temperatures and heat flux signatures are given in Figure 9.

a)

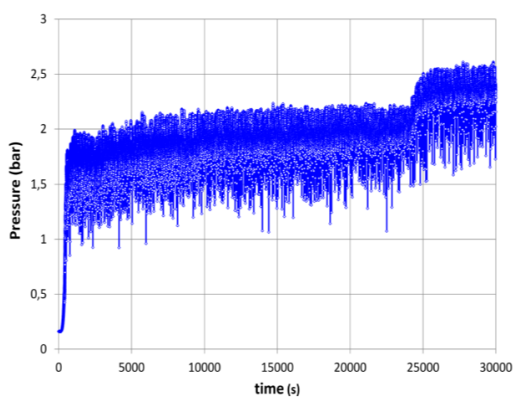

b)

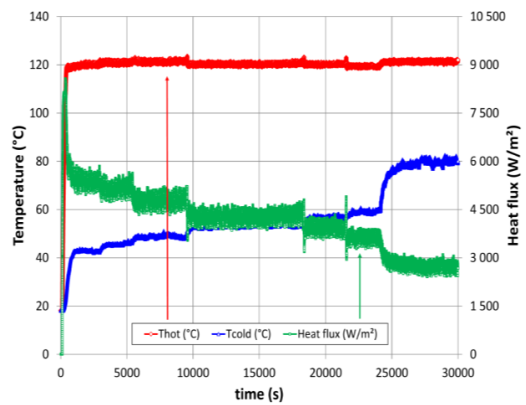

Figure 9: a) Pressure; b) temperatures and heat flux signatures for cooling reduction for $\mathrm{D} 2\left(\alpha=12.41 \%\right.$ and $\left.\mathrm{T}_{\text {hot }} \approx 120^{\circ} \mathrm{C}\right)$.

The influence of cooling diminution was studied on the D2 test section for two different hot temperatures. The results are presented in Figure 10.

It is possible to observe that for $\mathrm{T}_{\text {hot }} \approx 130^{\circ} \mathrm{C}$, the oscillations were not fully continuous (Figure 7) whereas for $\mathrm{T}_{\text {hot }} \approx 120^{\circ} \mathrm{C}$ the oscillations were always continuous for the all cooling range. The analyses of the behavior for $\mathrm{T}_{\text {hot }} \approx 130^{\circ} \mathrm{C}$ showed that the oscillating behavior was stabilized for a heat exchange coefficient between 25 and $35 \mathrm{~W} / \mathrm{m}^{2} / \mathrm{K}$.

When a sufficient heat exchange was attained the oscillations stabilized and further cooling does not improve the oscillations behavior very much (frequencies for $\mathrm{T}_{\text {hot }} \approx 130^{\circ} \mathrm{C}$ ). In the same manner the pressure amplitude variations changed very slightly with cooling reduction. 


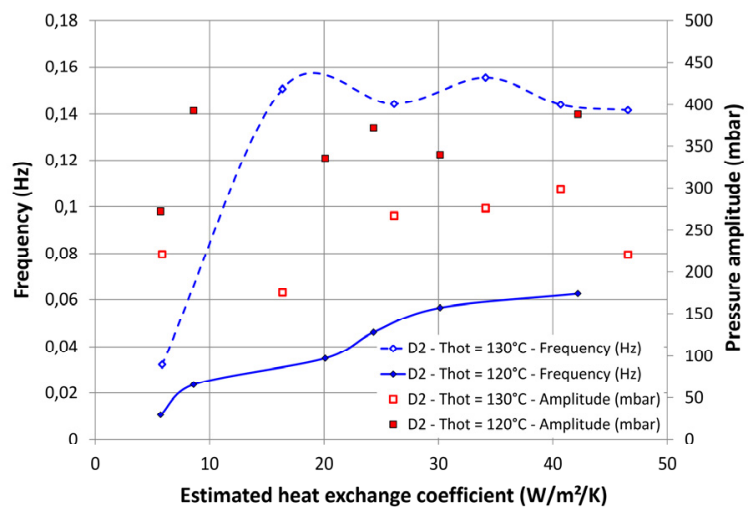

Figure 10: Influence of cooling on D2 for two different Thot $(\alpha=12.41 \%)$.

\section{Conclusions}

Oscillating test sections using sudden condensation phenomena have been fabricated in this work. These devices were separated into three parts: an evaporator which is in contact with a constant hot source, a thermal insulator which allowed the maintaining of a convenient temperature difference between hot and cold sources and a top cover in order to mount a pressure sensor for the pressure measurements. Pressure, heat flux variations and the temperature of cold and hot surfaces were analyzed in this study. The reasons for the appearance of the oscillations have been also given. Indeed, the selected devices' construction was one the main reason leading to their incipience. A parametric study had also been realized and the parameters which have been varied are: liquid filling ratio, hot source temperature, cooling level and device dimensions (two test sections were fabricated). The observed frequencies were in the range of $0.01 \mathrm{~Hz}$ to $0.15 \mathrm{~Hz}$, and the pressure amplitudes were in the range of $94.8 \mathrm{mbar}$ to $987.1 \mathrm{mbar}$. The results had shown that the device reduction from D1 (filling capacity $=15.14$ $\mathrm{x} 1 \mathrm{e}^{-9} \mathrm{~m}^{3}$ ) to $\mathrm{D} 2$ (filling capacity $=6.45 \times 1 \mathrm{e}^{-9} \mathrm{~m}^{3}$ ) improved the oscillation frequency and slightly diminished the pressure amplitude variations for the same filling ratio, heating and cooling conditions. The increase of these oscillation frequencies could open the way to energy harvesting by using this pressure drop to generate repeatable strains on a piezo-element.

\section{Acknowledgement}

This work was partly support by the French Inter-Ministerial Fund (FUI) through the HEATec project, which is gratefully acknowledged.

\section{References}

[1] Monfray, S., Puscasu, O., Savelli, G., Soupremanien, U., et al., Innovative thermal energy harvesting for zero power electronics, in Silicon Nanoelectronics Workshop. 2012, Silicon Nanoelectronics Workshop (SNW), 2012 IEEE: Honolulu, Hl. pp. 1-4. 
[2] Hudak, N.S. and Amatucci, G.G., Small-scale energy harvesting through thermoelectric, vibration, and radiofrequency power conversion. Journal of Applied Physics, 2008. 103 (101301).

[3] Formosa, F., Badel, A. and Favreliere, H., Development of low frequency, insulating thick diaphragms for power MEMS applications. Sensor and Actuators A: Physical, 2013. 189: pp. 370-379.

[4] Whalen, S., Thompson, M., Bahr, D., and Richards, C., Design, fabrication and testing of the P3 micro heat engine. Sensor and Actuators A: Physical, 2003. 104: pp. 290-298.

[5] Huesgen, T., Ruhhammer, J., Biancuzzi, G., and Woias, P., Detailed study of a micro heat engine for thermal energy harvesting. Journal of micromechanics and microengineering, 2010. 20 (104004).

[6] Hsieh, J.C., Lin, J.L., Shen, S.C., and Lin, D.T.W., The Study of the Enhancement of Micro-Vibration-Induced Harvester based on Vapor Impacting, in NEMS. 2013: Suzhou, China.

[7] Arnaud, A., Boisseau, S., Monfray, S., Puscasu, O., et al., Piezoelectric and electrostatic bimetal-based thermal energy harvesters in PowerMEMS 2013 Journal of Physics: Conference Series 012062.

[8] Puscasu, O., Monfray, S., Maitre, C., Cottinet, P.J., et al., A disruptive technology for thermal to electrical energy conversion. Microelectronics Journal, 2014. 45: pp. 554-558.

[9] Yang, H., Khandekar, S., and Groll, M., Performance characteristics of pulsating heat pipes as integral thermal spreaders. International Journal of Thermal Sciences, 2009. 48: pp. 815-824.

[10] Maydanik, Y.F., Dmitrin, V.I., and Pastukhov, V.G., Compact cooler for electronics on the basis of a pulsating heat pipe. Applied Thermal Engineering, 2009. 29: pp. 3511-3517.

[11] Lin, Z., Wang, S., Chen, J., Huo, J., et al., Experimental study on effective range of miniature oscillating heat pipes. Applied Thermal Engineering, 2011. 31: pp. 880-886.

[12] Lips, S., Bensalem, A., Bertin, Y., Ayel, V., et al., Experimental evidences of distinct heat transfer regimes in pulsating heat pipes (PHP). Applied Thermal Engineering, 2010. 50: pp. 900-907.

[13] Khandekar, S., Gautam P.A, and Sharma, P.K., Multiple quasi-steady states in a closed loop pulsating heat pipe. International Journal of Thermal Sciences, 2009. 48.

[14] Almenas, K., Pabarcius, R., and Seporaitis, M., Design and Tests of a Device for the Generation of Controlled Condensation Implosion Events. Heat Transfer Engineering, 2007. 27(3): pp. 32-41.

[15] Barna, I.F., Imre, A.R., Baranyai, G., and Ezsol, G., Experimental and theoretical study of steam condensation induced water hammer phenomena. Nuclear Engineering and Design, 2010. 240: pp. 146-150.

[16] Rogers, T.M., Elder, K.R., and Desai, R.C., Droplet growth and coarsening during heterogeneous vapor condensation. Physical Review A, 1988. 38: pp. 5303-5309. 